\title{
Chemical Proteomic Approaches Targeting Cancer Stem Cells: A Review of Current Literature
}

\author{
HYE JIN JUNG \\ Department of BT-Convergent Pharmaceutical Engineering, Sun Moon University, \\ Asan, Republic of Korea
}

\begin{abstract}
Cancer stem cells (CSCs) have been proposed as central drivers of tumor initiation, progression, recurrence, and therapeutic resistance. Therefore, identifying stem-like cells within cancers and understanding their properties is crucial for the development of effective anticancer therapies. Recently, chemical proteomics has become a powerful tool to efficiently determine protein networks responsible for CSC pathophysiology and comprehensively elucidate molecular mechanisms of drug action against CSCs. This review provides an overview of major methodologies utilized in chemical proteomic approaches. In addition, recent successful chemical proteomic applications targeting CSCs are highlighted. Future direction of potential CSC research by integrating chemical genomic and proteomic data obtained from a single biological sample of CSCs are also suggested in this review.
\end{abstract}

Cancer stem cells (CSCs) are tumor cells that possess stem cell properties of self-renewal and multi-lineage differentiation. They are functionally highly efficient in initiating tumor xenografts in vivo (1-4). Accumulating evidence has demonstrated that CSCs could cause treatment failure, relapse, and poor prognosis of many solid tumors. Thus, CSCs have been the focus of recent cancer research (5-7).

This article is freely accessible online.

Correspondence to: Hye Jin Jung, Department of BT-Convergent Pharmaceutical Engineering, Sun Moon University, 70, Sunmoonro 221, Tangjeong-myeon, Asan-si, Chungnam, 336-708, Republic of Korea. Tel: +82 415302354, Fax: +82 415302939, e-mail: poka96@sunmoon.ac.kr

Key Words: Cancer stem cells, chemical proteomics, glycoproteomics, phosphoproteomics, epithelial to mesenchymal transition, review.
CSCs have been identified and validated in various solid tumors and hematological cancers such as brain tumors, melanoma, ovarian cancer, breast cancer, colon cancer, liver cancer, and leukemia (8-14). These cells can be enriched in serum-free suspended culture conditions that allow formation of tumorspheres over several days or weeks (15-17). They can be characterized by specific surface markers and signal transduction pathways that are significant in stem cell biology. Cell surface markers including CD133, CD44, CD34, CD24, ATP-binding cassette B5 (ABCB5), and epithelial cell adhesion molecule (EpCAM) have been proven useful for isolating CSC-enriched populations from solid and hematological tumors (18-23). In normal stem cells, stemness signaling pathways are strictly regulated with intact genetics. However, stemness signaling pathways in CSCs are aberrantly regulated and consequently allow these cells to self-renew and differentiate into cancer cells. Dysregulated stemness signaling pathways contribute to resistance of CSCs to cancer treatment such as chemotherapy and radiation therapy. They also contribute to cancer recurrence and metastasis (24). Central stemness signaling pathways related to increased stemness property and tumorigenicity of CSCs include Janus-activated kinase/signal transducer and activator of transcription (JAK/STAT), Wnt/ $\beta$-catenin, Hedgehog, Notch, and TGF- $\beta$ (25-29). However, identification and isolation of CSC population in various human tumor types are still challenging due to the lack of definitive CSC markers. Follow-up studies of CSC-relevant signal transduction pathways are required to identify and verify novel biomarkers or therapeutic targets for effective cancer treatment.

Recently, mass spectrometry-based proteomics has been widely applied to generate comprehensive insight into the CSC proteome (30-32). This platform has led to identification of new protein biomarkers and signaling pathways to target CSCs. Among different fields of proteomics, chemical proteomics is becoming a powerful means for identifying proteome-wide drug-target 
interactions in CSCs. In the last decade, a chemical proteomic approach has been successfully applied to understand CSC biology and explore modes of action of small molecule drugs and their targets in CSCs. As shown in Figure 1, chemical proteomics strategies could employ several different experimental procedures, including global proteome comparison between drug treated and control cells and affinity based target protein profiling using modified or unmodified compound of interest $(33,34)$. As a consequence, these applications could be used to explore drug effects on the proteome of CSCs and find potential protein markers or therapeutic targets for CSCs.

The aim of this review was to provide an overview of CSC proteomics studies based on chemical biology with potential in CSC targeting therapy. In particular, it summarizes recent progresses in the application of chemical proteomic strategies focusing on drug-protein interactions, protein post-translational modifications such as glycosylation and phosphorylation, metabolic target identification, and epithelial to mesenchymal transition in CSCs (Table I).

\section{Chemical Proteomic Techniques}

In recent years, chemical proteomic strategies employing mass spectrometry or protein chip platform have contributed significantly to CSC research not only by facilitating the identification of CSC specific surface markers, but also by exploring molecular basis of signal transduction pathways involved in CSC maintenance. In addition, these strategies have emerged as powerful tools for large-scale identification of proteome-wide drug-protein interactions and elucidation of complex underlying mechanisms of drug action against CSCs.

Main chemical proteomic techniques include gel-based and gel-free methods. Gel-based methods employ one- or two-dimensional gel electrophoresis (2-DE) followed by mass spectrometry (MS) $(35,36)$. In 2-DE, proteins are separated by two different physicochemical parameters: isoelectric focusing and molecular weight. Following suitable separation and gel staining, proteins of interest are isolated from the gel, digested, and subjected to MS. Particularly, ionization methods such as matrix-assisted laser desorption ionization (MALDI) and electrospray ionization (ESI) in combination with time-of-flight (TOF) mass spectrometry or tandem mass spectrometry (MS/MS) detection have become standard methods to identify proteins of interest $(37,38)$. To improve protein separation resolution and reproducibility of conventional 2-DE, two-dimensional difference in gel electrophoresis (2D-DIGE) has been developed (39). In this method, protein samples labeled by different fluorescent dyes are mixed with identical concentrations and co-separated during the same 2-DE process. A comparison of generated 2D-DIGE fluorescence images allows for quantification of each spot. Thus, 2D-
DIGE can reduce gel-to-gel variation by permitting simultaneous separation and comparison of several samples on one gel.

On the other hand, quantitative proteomic analyses eliminate the need to visualize target proteins by gel electrophoresis. After protein extraction, tryptic peptides can be analyzed by liquid chromatography (LC) coupled to MS/MS (40, 41). This detection method allows for high resolution separation of hundreds of proteins to be quantified concurrently, thereby precisely revealing differential protein expression profiles. LC-based MS may be performed without labeling. For quantitative comparison of a number of samples at the same time, several popular peptide labeling methods can be utilized. These methods employ isotopic labeling of proteins which can then be differentiated by LC-MS/MS. Isotope labeling can be broadly divided into metabolic labeling and chemical labeling. In stable isotope labeling by amino acids in cell culture (SILAC), the whole proteome is labeled by metabolic incorporation of isotopically stable and nonradioactive forms of amino acids (42). Up to three biological samples can be compared directly using different isotopic forms of amino acids arginine and lysine. Isotopecoded affinity tag (ICAT) labeling is an isotopic labeling method that uses chemical labeling reagents (43). Paired protein samples are isotope-labeled with tags that can covalently bind to cysteine residues. These tags are similar in structure. However, their chemical properties such as mass are different. This technique analyzes relative amounts of cysteine-containing peptides in tryptic digests of paired protein extracts. Isobaric tags for relative and absolute quantitation (iTRAQ) method utilizes a multiplexed isobaric chemical tagging reagent to label primary amines of peptides and proteins (44). iTRAQ reagents usually consist of an $\mathrm{N}$ methyl piperazine reporter group, a balance group, and an $\mathrm{N}$ hydroxysuccinimide ester group. The balance group present in each iTRAQ reagent makes labeled peptide from each sample isobaric. Quantification is facilitated through analyzing reporter groups generated upon fragmentation in the mass spectrometer. This method particularly allows multiplexing of two to eight protein samples.

Reverse-phase protein array (RPPA), another promising chemical proteomic approach, has been increasingly used to determine deregulated signaling networks in CSCs (45). Protein array may also provide information on post-translational modifications of target proteins (46). This platform allows for quantification of total proteins or phosphoproteins in multiple samples under the same experimental conditions. In RPPA procedure, protein samples are robotically spotted onto specific surfaces. They are then probed with appropriate primary and secondary antibodies in a detection/amplification system. Accordingly, quantitative chemical proteomics have accelerated the identification of novel protein biomarkers and signaling pathways targeting CSCs. 

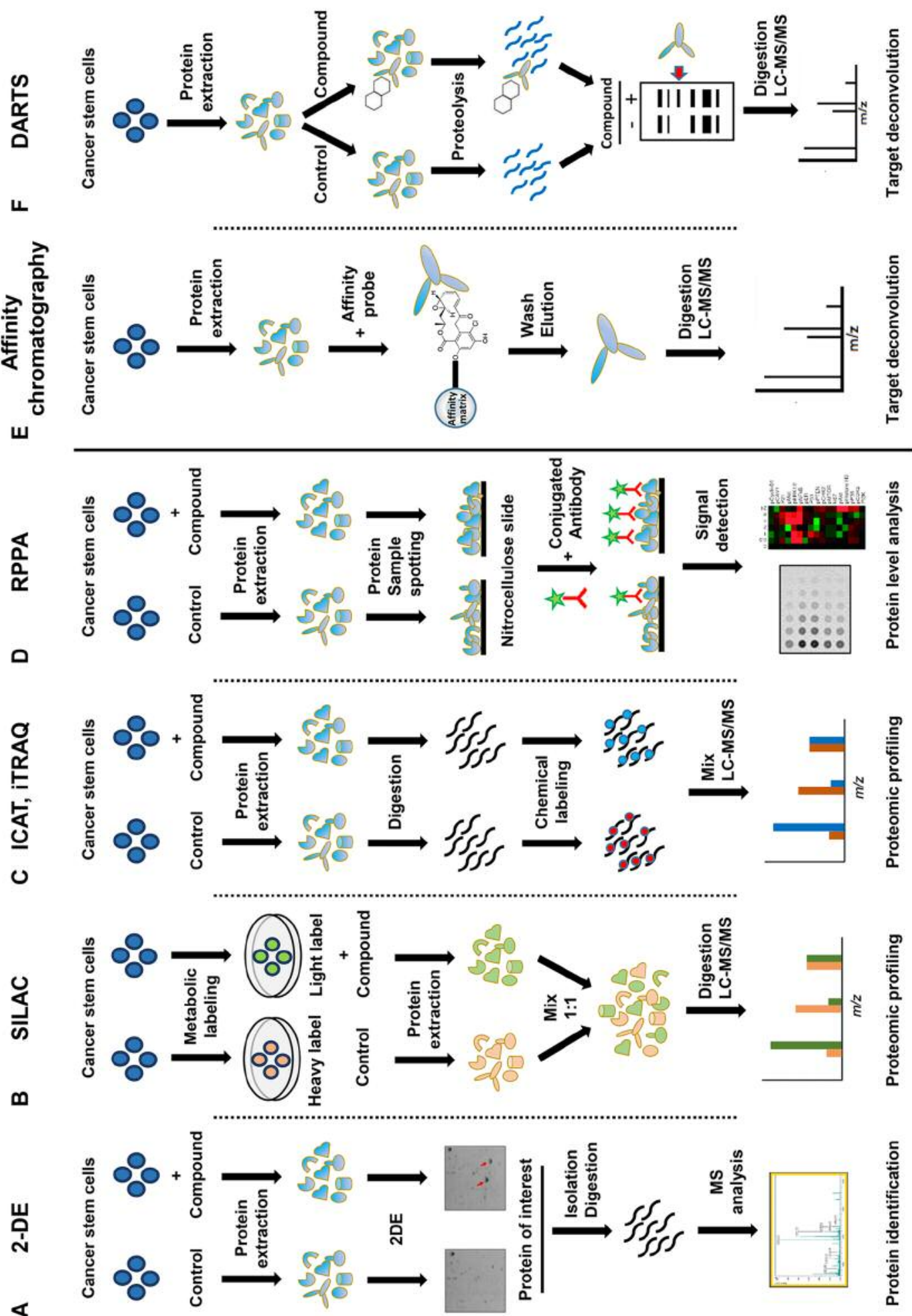

Figure 1. Major chemical proteomic methodologies utilized to study CSCs. Chemical proteomics strategies could employ different experimental procedures, including global proteome comparison between drug treated and control cells (A-D) and affinity-based target protein profiling using modified $(E)$ or unmodified $(F)$ compound of interest. Main chemical proteomic techniques include gel-based and gel-free methods. Gel-based methods employ 1- or 2-D gel electrophoresis followed by MS (A). Quantitative proteomic analyses eliminate the need to visualize target proteins by gel electrophoresis. For quantitative comparison of a number of samples in parallel, several popular peptide labeling methods can be utilized. These methods employ isotopic labeling of proteins followed by identification by LC-MS/MS $(B, C)$. 
Table I. Recent chemical proteomic applications for targeting CSCs.

\begin{tabular}{|c|c|c|c|c|c|}
\hline Application & Cancer type & Chemical & Major result & Methodology & Ref. \\
\hline \multirow[t]{2}{*}{$\begin{array}{l}\text { Affinity-based } \\
\text { chemical proteomics }\end{array}$} & $\begin{array}{l}\text { Chronic myeloid } \\
\text { leukemia }\end{array}$ & $\begin{array}{l}\text { Imatinib } \\
\text { Nilotinib } \\
\text { Dasatinib }\end{array}$ & $\begin{array}{l}\text { Revealed novel kinase } \\
\text { (DDR1) }\end{array}$ & $\begin{array}{c}\text { Affinity purification and } \\
\text { nonkinase targets (NQO2) } \\
\text { LC-ESI-MS/MS }\end{array}$ & (49) \\
\hline & Breast cancer & Isoliquiritigenin & $\begin{array}{l}\text { GRP78 mediates cancer drug } \\
\text { resistance and } \beta \text {-catenin } \\
\text { signaling in CSCs }\end{array}$ & $\begin{array}{c}\text { DARTS } \\
\text { MALDI-TOF MS }\end{array}$ & (52) \\
\hline \multirow[t]{2}{*}{ Glyco-proteomics } & $\begin{array}{l}\text { Glioblastoma } \\
\text { multiforme }\end{array}$ & $\begin{array}{l}\gamma \text {-secretase } \\
\text { inhibitor }\end{array}$ & $\begin{array}{l}\text { Identified the changes of } \\
\text { glycosylation patterns upon } \\
\text { Notch pathway blockade } \\
\text { in GBM CSCs }\end{array}$ & $\begin{array}{l}\text { Lectin microarray } \\
\text { Multi-lectin affinity } \\
\text { chromatography } \\
\text { Online nano-RPLC/LTQ MS }\end{array}$ & (66) \\
\hline & Hepatoma & Doxorubicin & $\begin{array}{c}\text { Identified glycoproteins } \\
\text { targeted for sialylation in } \\
\text { DXR-treated hepatoma cells }\end{array}$ & $\begin{array}{l}\text { iTRAQ } \\
\text { SSA lectin blotting } \\
\text { LC-MS/MS }\end{array}$ & (71) \\
\hline \multirow[t]{2}{*}{$\begin{array}{l}\text { Phospho- } \\
\text { proteomics }\end{array}$} & $\begin{array}{l}\text { FDCP-Mix } \\
\text { hematopoietic } \\
\text { progenitor cells }\end{array}$ & NSC23766 & $\begin{array}{l}\text { Identified a phosphorylation } \\
\text { event at S962 of PTPRC/CD45 which } \\
\text { is involved in stem cell motility }\end{array}$ & $\begin{array}{c}\text { iTRAQ } \\
\text { RP-LC-MS/MS }\end{array}$ & (79) \\
\hline & $\begin{array}{l}\text { Glioblastoma } \\
\text { multiforme }\end{array}$ & $\begin{array}{c}\text { TMZ } \\
\text { UCN-01 }\end{array}$ & $\begin{array}{l}\text { Combined PDK1 and CHK1 inhibition } \\
\text { is required to kill GBM CSCs }\end{array}$ & RPPA & (80) \\
\hline \multirow[t]{2}{*}{ CSC metabolism } & Breast cancer & Doxycycline & $\begin{array}{l}\text { Doxycycline targets both mitochondrial } \\
\text { ribosomes and DNA-PK, thereby } \\
\text { reducing energy metabolism in breast CSCs }\end{array}$ & $\begin{array}{l}\text { LTQ Orbitrap XL } \\
\text { LC-MS/MS }\end{array}$ & (85) \\
\hline & $\begin{array}{l}\text { Chronic myeloid } \\
\text { leukemia }\end{array}$ & BMS-214662 & $\begin{array}{c}\text { BMS-214662 treatment of CD34+ } \\
\text { CML cells resulted in the loss of nuclear } \\
\text { membrane integrity by causing } \\
\text { differential expression of nucleoporins }\end{array}$ & $\begin{array}{c}\text { iTRAQ } \\
\text { MALDI TOF/TOF MS }\end{array}$ & (95) \\
\hline \multirow[t]{3}{*}{ EMT } & $\begin{array}{l}\text { Non-small cell lung } \\
\text { carcinoma }\end{array}$ & $\begin{array}{l}\text { Erlotinib } \\
\text { Gefitinib }\end{array}$ & $\begin{array}{l}\text { Unlike gefitinib, erlotinib targets both } \\
\text { EGFR and IPP complex activities } \\
\text { in } E G F R \text { wild-type NSCLC }\end{array}$ & $\begin{array}{l}\text { Affinity purification } \\
\text { LC/MS }\end{array}$ & $(101)$ \\
\hline & $\begin{array}{l}\text { Tongue squamous } \\
\text { cell carcinoma }\end{array}$ & Plumbagin & $\begin{array}{l}\text { Plumbagin suppresses EMT and } \\
\text { stemness via inhibiting Nrf2- } \\
\text { mediated signaling pathway }\end{array}$ & $\begin{array}{c}\text { SILAC } \\
\text { LC-MS/MS }\end{array}$ & (103) \\
\hline & $\begin{array}{l}\text { Human adipose tissue- } \\
\text { derived mesenchymal } \\
\text { stem cells }\end{array}$ & $\begin{array}{l}\text { Lysophosphatidic } \\
\text { acid }\end{array}$ & $\begin{array}{l}\text { hASC-derived } \beta \text { ig-h } 3 \text { plays a key } \\
\text { role in tumor growth by regulating } \\
\text { tumor microenvironment }\end{array}$ & LC-MS/MS & (106) \\
\hline
\end{tabular}

\section{Chemical Proteomic Applications in CSCs}

Affinity-based chemical proteomic approach in CSCs. Chemical proteomic strategies through a combination of affinity chromatography and high-throughput MS analysis have emerged as powerful tools for identifying drug targets and elucidating complex underlying mechanisms of drug action against CSCs. Affinity-based chemical proteomics utilizes small molecule probes to capture and enrich specific target proteins from complex biological samples, enabling the identification of drug targets by proteomic techniques $(47,48)$.

Such an affinity-based chemical proteomic approach has led to the identification of target proteins of BCR-ABL inhibitors imatinib, nilotinib, and dasatinib in chronic myeloid leukemia (CML), a stem cell disease (49). This approach begins with structure-activity relationship (SAR) studies so that positions that do not alter the bioactivity of small molecules can be used for attachment to affinity tag or solid matrix. Analogues such as c-imatinib3, c-nilotinib, and c-dasatinib with primary amino groups have been synthesized for immobilization to sepharose beads. Their inhibitory potential on kinase activity of ABL kinase domain have been measured. After SAR study, affinity matrices of these three drug are then incubated with CML primary cell lysates, washed, eluted, and separated by SDSPAGE. Proteins are then identified by LC-ESI-MS/MS and database search. Further bioinformatics analysis has revealed novel kinase and non-kinase targets for these three drugs. Among these targets, inhibition of receptor tyrosine 
kinase DDR1 by nilotinib and dasatinib and inhibition of oxidoreductase NQO2 by imatinib and nilotinib have been demonstrated through corresponding enzymatic assays (49). Chemical proteomic profiling of native targets in leukemia stem cells for these three clinical drugs targeting BCR-ABL could be used to understand the molecular mechanism of action of these drugs and predict clinical outcomes and side effects of drugs.

However, affinity chromatography approaches require chemical modification of small molecules to introduce affinity tags. Many compounds cannot be substantially modified without losing biological activity or target specificity. To overcome this limitation, a simple and widely applicable approach has been developed for target identification. Drug-affinity responsive target stability (DARTS) can be used to analyze direct binding of a small molecule to its target protein without requiring modification or immobilization of the small molecule $(50,51)$. This labelfree method is based on the concept that a target protein bound to a small molecule might be less susceptible to proteolysis than such protein in its unbound state. Consequently, the enhanced stability due to small-molecule binding can result in specific protection for the target protein against protease digestion. Differences in proteolysis patterns between compound-treated and control protein samples digested with various amounts of protease can be analyzed by LC-MS/MS.

Using the DARTS strategy, GRP78 has been identified as a direct target of natural compound isoliquiritigenin (ISL) in breast CSCs (52). GRP78 is one isoform of Hsp70. It is predominantly located in the endoplasmic reticulum where it plays a role in protein folding and degradation of misfolded proteins (53). GRP78 also plays a critical role in mediating tumor proliferation, angiogenesis, and metastasis (54). Subsequent molecular docking analysis and functional studies have demonstrated that ISL could bind to the ATPase catalytic domain of GRP78 and inhibit its ATPase activity, resulting in its dissociation from $\beta$-catenin (52). Thus, ISL can chemosensitize breast CSCs via inducing $\beta$-catenin proteasome degradation. Indeed, targeting aberrant $\beta$-catenin signaling in CSCs has become a promising strategy to improve chemosensitivity of cancer during treatment. These findings therefore highlight the significance of GRP78 in mediating cancer drug resistance and $\beta$-catenin signaling in CSCs.

Glycoproteomic analysis of CSCs. Glycosylation is one of the most complex and common forms of protein posttranslational modifications. Glycoproteins are ubiquitously distributed in various tissues and cells. They are primarily localized on the cell surface (55-57). Glycoproteins play a pivotal role in many biological processes such as cell adhesion, trafficking, cell signaling, pathogen recognition, and immune response. According to accumulating studies, alterations in glycoproteins are not only related to malignant transformation and tumor propagation, but also related to cancer stemness (58-60). Most known markers of CSCs are cell surface glycoproteins, indicating biological significance of glycoproteins for CSC functions $(61,62)$.

Glycoproteomics is uniquely focused on analyzing glycosylated proteins to reveal glycoproteome alterations. Mass spectrometry (MS) has been the most effective and versatile platform for analyzing both glycoproteins and structures of their glycan moieties. For the identification of glycoproteins, a typical glycoproteomics process consists of glyco-enrichment, MS analysis, and bioinformatics interpretation. Glyco-enrichment methods including lectin affinity chromatography and hydrazide chemistry can be applied to enrich glycoproteins from complex biological samples, thus increasing analytical sensitivity. In addition to the use of a single lectin to capture a particular form of glycan structure, multi-lectin chromatography using lectins with broad specificities has been applied to overcome the low affinity and lack of complete glycoprotein capture associated with single lectin chromatography (63-65).

Emerging technology of glycoproteomics has been recently applied to study changes of glycosylation patterns upon Notch pathway blockade by $\gamma$-secretase inhibitor (GSI) in glioblastoma multiforme (GBM) (66). Notch signaling has been demonstrated to have a central role in GBM CSCs. Blockade of this pathway by GSI can deplete GBM CSCs and prevent tumor propagation both in vitro and in vivo (67). Different strategies have been employed to target cell surface glycoproteins and intracellular membrane glycoproteins separately (66). Profiling of cell surface glycoproteins has been performed through fluorescent-assisted lectin microarray with a panel of 16 lectins, whereas profiling of glycoproteins from soluble fraction of cell lysates has been performed by coupling multi-lectin chromatography with a label-free quantitative MS method. The finding of downregulation of neural $\alpha$-glucosidase $\mathrm{AB}$ and $\beta$-galactosidase might suggest altered glycan processing, while reduced level of cathepsin D and increased expression of CD90 might imply attenuated proliferation and elevated apoptosis upon GSI treatment. Such study provides meaningful information regarding the influence of GSI treatment on glycosylation in GBM CSCs. It might lead to improved understanding of drug mechanism and identification of novel glycoprotein markers of these cells.

Alteration of sialylation, one of the most important types of glycosylation, is involved in carcinogenesis. Glycomic analysis using lectin microarray has revealed that sialylated glycans are useful markers for CSC-like cells in hepatocellular carcinoma $(68,69)$. Several studies have suggested that short-term treatment with anticancer drugs can be used to concentrate CSCs easily (70). To identify target glycoproteins showing increased sialylation upon 
doxorubicin (DXR) treatment, iTRAQ analysis can be performed (71). Total cell lysates from human hepatoma cell line Huh7 treated with or without DXR have been trypsinized and applied to Sambucus sieboldoana agglutinin (SSA) lectin-agarose column (71). Captured sialylated glycopeptides are then de-glycosylated with glycopeptidase $F$ and labeled with a specific isobaric iTRAQ reagent. Most of sialylated glycoproteins identified are found to be cancerassociated proteins. Through a further study using lectin blot analysis and SSA precipitation followed by LC-MS/MS of Huh7 cells treated with or without DXR, sialylated $70-\mathrm{kDa}$ proteins including beta-galactosidase and alpha-2-HSglycoprotein (fetuin-A) have been identified as specific target proteins. These sialylated glycoproteins might be used as new glycomarkers for hepatoma CSCs. Therefore, glycoproteomic analysis of chemical drug-treated CSCs could provide potential functions of glycoproteins in CSC biology as well as improved understanding for better therapeutic targeting of CSCs.

Phosphoproteomics approach in CSCs. In addition to glycosylation, phosphorylation is one of the most common and important post-translational modifications of proteins. It is involved in the regulation of cellular biological processes. Reversible protein phosphorylation plays a significant role in cellular signal transduction and modification of multiple protein functions $(72,73)$. However, aberrant regulation of protein phosphorylation is frequently associated with various cancers $(74,75)$. Specific protein phosphorylation may be critical to signaling networks that regulate CSC self-renewal, differentiation, and metastasis. Although several protein phosphorylation events that affect CSC signaling have been studied, large-scale analysis of differentially regulated protein phosphorylation in CSCs is needed to provide better understanding of complex disease mechanism and identify new biomarkers for developing efficient treatments.

To systematically study phosphoproteins, several highthroughput phosphoproteomic technologies such as reversephase protein arrays, phospho-specific flow cytometry, and mass spectrometry (MS)-based technologies have been developed (76-78). Among them, MS-based technologies have been used as major platforms to identify phosphoproteins and phosphosites at comprehensive, unbiased, and quantifiable level. The typical procedure for MS-based phosphoproteomic experiment can be divided into four stages: 1) sample preparation including cell fractionation and protein digestion; 2) enrichment of phosphopeptides via affinity purification; 3) analysis by LC coupled with tandem MS; and 4) identification of phosphoproteins and phosphosites using bioinformatics approach.

To uncover new mechanistic event relevant to primitive hematopoietic stem cell motile responses, a series of phosphoproteomic experiments have been employed.
Multipotent FDCP-Mix hematopoietic progenitor cell line is pretreated with or without Rac1/2 inhibitor NSC23766 and chemotactic agent CXCL12. Subcellular fractionation, iTRAQ labeling, and phosphopeptide enrichment are then sequentially carried out. Phosphorylated peptides are then analyzed by reverse phase (RP)-LC-MS/MS. From these analyses, a number of phosphoevents appear to be differentially regulated by treatment with CXCL12 and NSC23766 (79). Interpretation of proteomic datasets has led to the identification of phosphorylation event at S962 of PTPRC/CD45, a protein tyrosine phosphatase. It has been demonstrated that pS962 PTPRC/CD45 is activated by CXCL12 in a $\operatorname{Rac} 1 / 2$ dependent manner. It is a novel phosphorylation event that controls stem cell motility in normal and malignant hematopoiesis.

Among available technologies in phosphoproteomics, reverse-phase protein array (RPPA) is a technology platform designed for quantitative, multiplexed, and sensitive analysis of hundreds of phosphoproteins from a limited amount of sample $(45,46)$. A recent study has analyzed a diverse collection of GBM stem-like cell (GSC) lines by combining RPPA and small molecule kinase inhibitor library screening to identify and interrogate signaling pathways involved in GSC resistance to therapy (80). GSCs are treated with temozolomide (TMZ), a chemotherapy drug in standard adjuvant treatment for GBM. RPPA has been performed to detect changes in phosphorylation patterns associated with resistance. GSCs are resistant to TMZ because their pathway activation pattern involved in survival and proliferation is not influenced by TMZ treatment. A library of protein and lipid kinase inhibitors have been screened to identify specific targets involved in GSC survival and proliferation. Staurosporine derivative UCN-01 (7-hydroxy-staurosporine), one of PKC inhibitors, has been found to exhibit the most effective antiproliferative activity, yielding a range of sensitivity across GSC lines. To better understand the molecular mechanism underlying differential sensitivity of GSC lines to UCN-01, extensive RPPA analysis has been performed for GSC lines treated with UCN-01. Differently from TMZ, UCN-01 treatment has resulted in molecular changes in most GSC lines. RPPA data have shown that the sensitivity to UCN-01 is associated with activation of survival signals mediated by PDK1 and DNA damage response initiated by $\mathrm{CHK} 1$, thereby suggesting a rationale for simultaneous targeting of PDK1 and CHK1 pathways. Taken together, quantitative phosphoproteomic profiling of small molecule inhibitors can assist in the determination of aberrantly activated signaling pathways and therapeutic targets in CSCs.

Proteomic analysis of CSC metabolism. Understanding CSC physiology and metabolism may be crucial for developing novel and effective cancer therapies. Several recent studies 
have aimed to define properties of CSC mitochondria and identify specific mitochondrial targets for CSC elimination. An unbiased label-free proteomics analysis has revealed that mammospheres (a population of cells enriched in cancer stem cells and progenitor cells) from two estrogen receptor (ER)-positive breast cancer cell lines functionally overexpressing numerous mitochondrial proteins are related to mitochondrial biogenesis, electron transport, oxidative phosphorylation, ATP synthesis, beta-oxidation, and ketone re-utilization (81). The potential clinical relevance of these metabolic targets has been further validated using a previously published dataset of patient breast cancer samples. In addition, pharmacological approaches using specific MCT1/2 inhibitor (AR-C155858) and mitochondrial ATP synthase inhibitor (oligomycin A) have functionally verified these proteomic observations. These results suggest that mitochondrial inhibitors might have potential in breast CSC treatment.

Doxycycline, a FDA-approved tetracycline antibiotic, functions as an inhibitor of mitochondrial biogenesis by binding to the small subunit of mitochondrial ribosome (8284). Doxycycline can effectively inhibit mammosphere formation in primary breast cancer samples derived from metastatic disease sites. To better understand the mechanism of action of doxycycline on CSC metabolism, an unbiased label-free chemical proteomics approach has been used to identify proteins effectively down-regulated by doxycycline. Doxycycline can significantly reduce the expression of many key protein targets functionally associated with mitochondrial metabolism, glycolysis, epithelial to mesenchymal transition (EMT), protein synthesis, DNA damage response, inflammation, and protein degradation in human breast cancer cells (85). In particular, doxycycline can remarkably reduce DNA-PK protein expression. DNA-PK is the catalytic subunit of DNA-dependent protein kinase involved in DNA-repair $(86,87)$. DNA-PK is associated with the maintenance of integrity and copy number of mitochondrial DNA. It can also confer radio-resistance in cancer cells $(88,89)$. Inhibition of DNA-PK by doxycycline, accordingly suppresses both oxidative mitochondrial metabolism and glycolysis and increases the sensitivity of breast CSCs to radiation. Furthermore, DNA-PK is significantly over-expressed in breast cancer mammospheres. Genetic or pharmacological inhibition of DNA-PK can block mammosphere formation (85). Doxycycline also inhibits multiple signaling pathways involved in self-renewal and drug resistance of CSCs such as Sonic Hedgehog, Notch, Wnt, and TGF- $\beta$ signaling (85). In conclusion, doxycycline may target both mitochondrial ribosomes and DNA-PK, thereby reducing energy metabolism in breast CSCs. Overall, these findings suggest that clonal expansion and survival of CSCs are dependent on mitochondrial biogenesis. Therefore, mitochondria are promising therapeutic targets for eradicating CSCs.
Nuclear pore complexes (NPCs) are large multiprotein channels that can penetrate nuclear envelope (NE). Proteins and RNA can cross the NE in a tightly regulated process by migrating through NPCs. NPCs are considered to be gatekeepers of the nucleus. They are responsible for almost all transport between the nucleoplasm and cytoplasm, consequently affecting a variety of nuclear processes and metabolism such as chromatin silencing, transcriptional regulation, and DNA damage repair $(90,91)$. Nucleoporins, structural components of NPCs, have been linked to a multitude of cancers through chromosomal translocation that generates fusion proteins, changes in protein expression levels, and single point mutations $(92,93)$. However, mechanistic details of their functions in CSCs remain poorly understood.

Recently, a farnesyl transferase inhibitor BMS-214662 has been identified as a selective inducer of apoptosis in leukemic stem cells of chronic myeloid leukemia (CML) patients (94). In order to elucidate the mode of action of BMS-214662 in $\mathrm{CD}^{+} 4^{+}$cells from CML patients, a proteomic approach based on iTRAQ has been employed to analyze changes in protein expression in response to drug treatment in nuclear and cytoplasmic fractions of two distinct CD $34^{+}$CML cells (95). After iTRAQ labeling, combined cytoplasmic or nuclear proteins are fractionated by extensive 2D LC and analyzed using MALDI TOF/TOF MS. Altered proteins after drug treatment are involved in nucleic acid metabolism, oncogenesis, developmental processes, and intracellular protein trafficking. In iTRAQ analysis, nucleoporins have been observed to be differentially expressed. Interestingly, BMS-214662 treatment of CD34 ${ }^{+}$ CML cells has resulted in altered distribution of nuclear proteins into the cytoplasm. It also has resulted in altered distribution of cytoplasmic proteins into the nucleus, indicating that the observed mislocalization of proteins in response to BMS-214662 might be associated with loss of nuclear membrane integrity caused by differential expression of nucleoporins. These results suggest that alterations in protein localization might have contributed to the apoptotic effect of BMS-214662 on CML stem cells.

Proteomic analysis of EMT. Epithelial to mesenchymal transition (EMT), a highly conserved cellular process that transforms epithelial cells into mesenchymal cells, is involved in normal embryogenesis and tissue repair. It also contributes to tumor metastasis and progression (96). Recent studies have highlighted a link between EMT and CSC formation (97-99). EMT is related to the acquisition and maintenance of stem cell-like characteristics. EMT can endow differentiated normal and cancer cells with stem cell properties, including the ability to self-renew and initiate tumors. Furthermore, CSCs often display EMT characteristics such as loss of adhesion protein E-cadherin, 
enabling cancer cells to metastasize easily and quickly. Such reciprocal relationship between EMT and CSCs might have numerous implications in the progression, recurrence, and therapy resistance of tumors. Several chemical proteomic studies have revealed potential protein targets to control EMT in cancer.

Erlotinib and gefitinib are tyrosine-kinase inhibitors (TKIs) that can directly inhibit epidermal growth factor receptor (EGFR). However, erlotinib is effective in patients with $E G F R$ wild-type or mutated tumors, whereas gefitinib is only beneficial for patients with activating mutations (100). To determine the effect of these differences on clinical outcomes, a quantitative chemical proteomics method has been applied to erlotinib and gefitinib using wild-type EGFR-expressing non-small cell lung carcinoma (NSCLC) cell lines (101). The TKIs have been covalently linked to Sepharose beads to generate affinity matrices. Cell lysates are pre-incubated with increasing concentrations of unmodified erlotinib or gefitinib and then fractionated on respective affinity matrix. Captured proteins are then eluted, separated by SDS-PAGE, and finally identified by LC/MS. Chemical proteomics profiling has shown that, unlike gefitinib, erlotinib can interact with the ternary complex formed by integrin-linked kinase (ILK), $\alpha$ parvin, and PINCH (IPP). The IPP complex is involved in EMT. Erlotinib sensitivity has been found to be correlated with EMT status. Further experiment using EMT-inducible cellular model has shown that erlotinib can prevent EMT more effectively than gefitinib by inhibiting the loss of Ecadherin and blocking the increase of IPP complex levels. These findings suggest that, unlike gefitinib, erlotinib targets both EGFR and IPP complex in EGFR wild-type NSCLC, thus slowing down the metastatic process of epithelial tumors.

Plumbagin (PLB) is a natural naphthoquinone compound that has a wide spectrum of pharmacological activities, including anticancer effects in in vitro and in vivo models (102). To elucidate potential molecular targets and underlying mechanisms of PLB in the treatment of tongue squamous cell carcinoma (TSCC), SILAC-based quantitative proteomic approach has been employed (103). TSCC cell line SCC25 is cultured in the medium with or without stable isotope-labeled amino acids $\left({ }^{13} \mathrm{C}_{6} \mathrm{~L}\right.$-lysine and ${ }^{13} \mathrm{C}_{6}{ }^{15} \mathrm{~N}_{4} \mathrm{~L}$ arginine). These cells are then treated with PLB and lysed. After equal amounts of heavy and light protein sample are combined and digested, LC-MS/MS analysis is then performed. Proteomic data have revealed that PLB treatment can significantly modulate the expression of critical proteins that regulate cell cycle, apoptosis, and EMT signaling pathways in SCC25 cells (103). PLB increases expression levels of E-cadherin, claudin-1, and ZO-1. However, PLB decreases the expression levels of $\mathrm{N}$-cadherin, snail, slug, TCF-8/ZEB1, $\beta$-catenin, and vimentin known to key regulators of EMT. In addition, the stemness-attenuating effect of PLB in SCC25 cells has been demonstrated. PLB has been found to significantly decrease expression levels of key stemness markers such as Oct-4, Sox-2, Nanog, and Bmi-1. Quantitative SILAC-based proteomic approach has also provided significant clue that PLB might be able to suppress EMT and stemness via inhibiting nuclear factor erythroid 2-related factor 2 (Nrf2)-mediated signaling pathway in human TSCC cells.

Lysophosphatidic acid (LPA)-activated mesenchymal stem cells can promote tumorigenic potentials of cancer cells through a paracrine mechanism $(104,105)$. In order to clarify LPA-stimulated paracrine mechanisms involved in the crosstalk between human adipose tissue-derived mesenchymal stem cells (hASCs) and cancer cells, secreted proteins included in LPA-conditioned medium (CM) from hASCs have been identified using LC-MS/MS proteomic analysis. LPA-induced proteins include extracellular matrix proteins, proteases and protease inhibitors, and proteins involved in cytokine signaling (106). Particularly, further experiments have demonstrated the pivotal role of an extracellular matrix protein, $\beta$ ig-h3, as an LPA-induced paracrine factor of hASCs on adhesion and proliferation of A549 human lung adenocarcinoma cells. These results suggest that hASC-derived $\beta$ ig-h3 plays a key role in tumor growth by regulating tumor microenvironment. Therefore, $\beta$ ig-h3 might be useful as a biomarker for lung cancer.

\section{Conclusion}

CSCs have been proposed to be cancer-initiating cells responsible for tumor development and metastasis. They contribute to resistance of cancer to standard anticancer therapies (1-7). In this regard, CSCs might be the most crucial target for developing treatment of cancer. Recently, chemical proteomic research has improved our knowledge about CSC behavior and CSC targeted therapy strategies by studying different aspects of CSC biology. Chemical proteomics utilizes modified or unmodified small molecule probes to characterize proteome-wide drug-protein interactions. Proteomic techniques can provide information about expression, functions, interactions, and posttranslational modifications of target proteins $(33,34)$. This review briefly introduced chemical proteomic methodology with high sensitivity, specificity, and throughput. It also described recent progress in CSC proteome studies focusing on affinity capture of drug targets, glycoproteomics, phosphoproteomics, metabolic targets, and EMT using chemical proteomic methods. Such chemical proteomic strategies have been successfully applied for the identification of CSC-specific biomarkers or therapeutic targets, thus providing better understanding of CSC-relevant biological features or signaling pathways.

In the last decade, proteomic analysis has become an essential tool for investigating cancer biology, complementing 


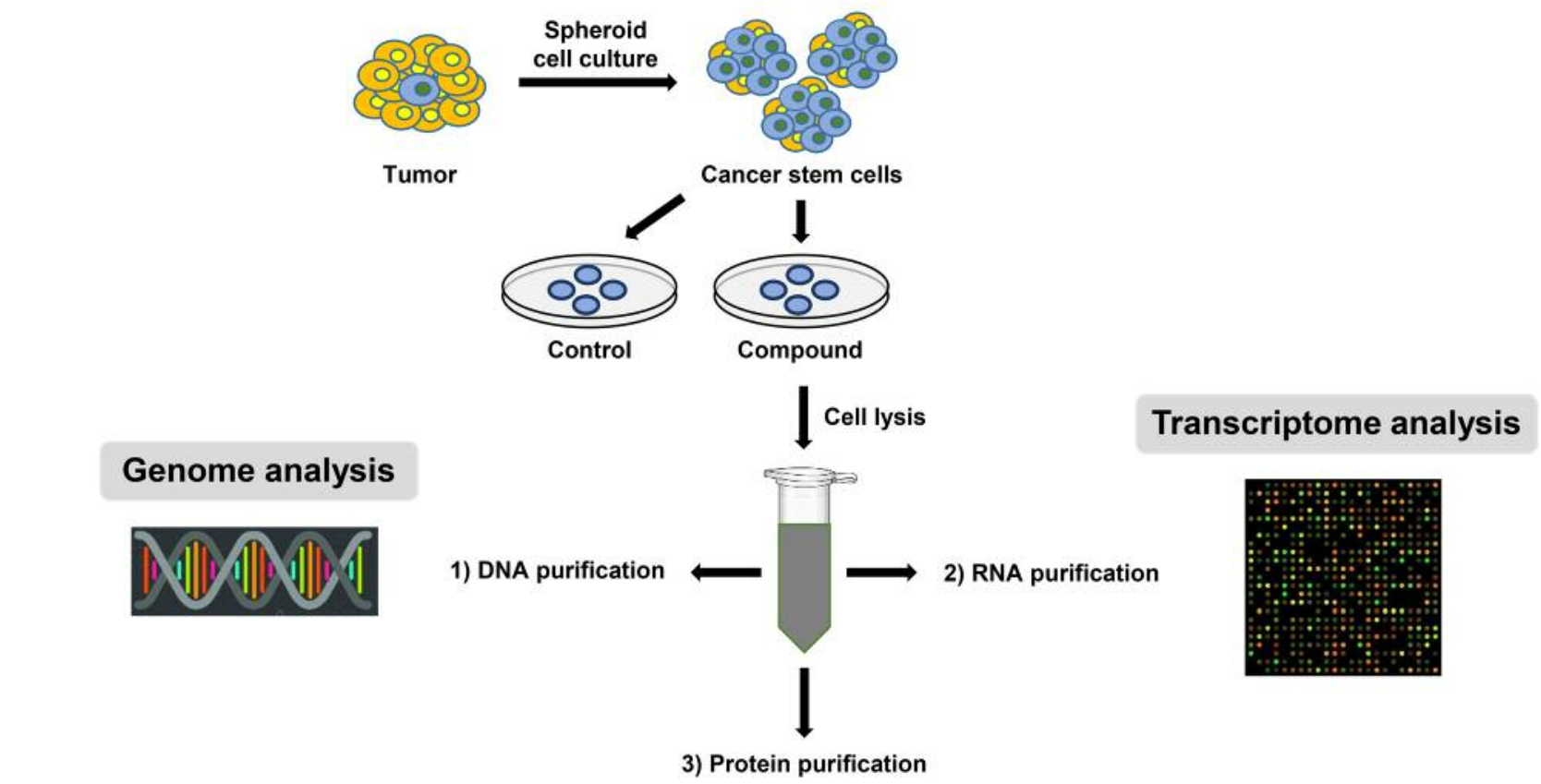

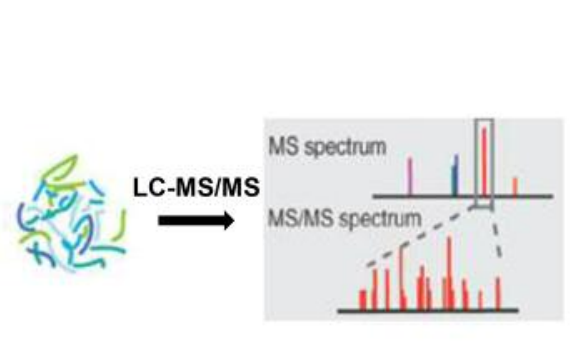

Proteome

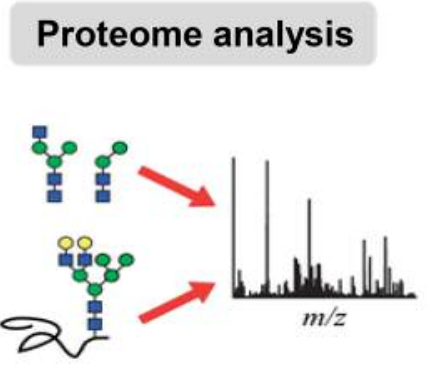

Glycoproteome

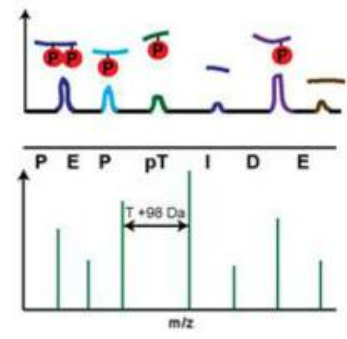

Phosphoproteome

Figure 2. Workflow for an integrated analysis of chemical genomic and proteomic data obtained from a single biological sample of CSCs. The first step is to efficiently isolate and enrich tumor-initiating cells from diverse tumor types or established cancer cell lines. These biological samples are then lysed. DNA, RNA, and proteins are then extracted from a single sample in different phases. This workflow provides all-in-one analysis of genome, transcriptome, and proteome from a single biological sample.

genetic analysis. Gene expression levels are not necessarily correlated with the expression levels of corresponding proteins (107). Furthermore, post-translational modifications of proteins such as phosphorylation, glycosylation, acetylation, and protein cleavage cannot be detected at the gene levels. However, they play prominent roles in protein stability, functions, interactions, and localization. Moreover, proteins represent more functionally relevant therapeutic targets than DNA or RNA (108). For this reason, proteomic studies are fundamental to obtain accurate understanding of cellular physiological and pathological processes. Nevertheless, integrated analysis of genomic, transcriptomic, and proteomic studies in CSC samples would provide comprehensive molecular understanding of pathogenesis of CSCs by identifying genetic defects in genome, evaluating transcriptional expression profiles of genes, and detecting translational and posttranslational modifications of their encoded proteins. Therefore, a workflow for identifying genes and proteins necessary for the maintenance of CSCs is proposed (Figure 2). The first step is to efficiently isolate and enrich tumor-initiating cells from diverse tumor types and established cancer cell lines. Biological samples are then lysed. Biomolecules including DNA, RNA, and proteins are then extracted from a single sample in different phases. Accordingly, this workflow can be used to provide an all-in-one analysis of genome, transcriptome, and proteome from a single biological sample to discover potential CSC specific biomarkers and aberrant stemness signaling pathways. By using improved and sensitive 
analytical methods, accurate integration of genomic and proteomic data and their functional interpretation together with clinical evaluations might permit more complete understanding of complex biological processes responsible for CSC behavior. Therefore, combined analysis of chemical genomic and proteomic data might be able to produce more reliable clues to attack CSCs.

Unlike other proteomic approaches, chemical proteomics could serve as powerful tools in overall target profiling and molecular regulatory network elucidation of drug candidates. Chemical proteomics is also advantageous in clarifying modes of action of anticancer drugs to eliminate CSCs. It can also provide more precise understanding of drug sideeffects and drug resistance to CSCs.

In spite of enormous biological and clinical significance of CSCs, molecular mechanisms maintaining CSCs now only begin to emerge. Many questions remain unresolved. In addition, extreme heterogeneity of human cancers needs establishment of more definite CSC-relevant in vitro and in vivo models to allow adequate maintenance and propagation of CSCs. Ongoing chemical proteomic research toward CSC eradication will enhance our understanding of CSC biology to develop effective CSCtargeted therapies.

\section{Acknowledgements}

This work was carried out with the support of "Cooperative Research Program for Agriculture Science and Technology Development (Project No. PJ01188001)" funded by Rural Development Administration, Republic of Korea. It was also supported by a grant (NRF-2016R1D1A1B03932956) of the Basic Science Research Program through the National Research Foundation of Korea (NRF) funded by the Ministry of Education, Republic of Korea.

\section{References}

1 Reya T, Morrison SJ, Clarke MF and Weissman IL: Stem cells, cancer, and cancer stem cells. Nature 414: 105-111, 2001.

2 Clevers H: The cancer stem cell: premises, promises and challenges. Nat Med 17: 313-319, 2011.

3 Lobo NA, Shimono Y, Qian D and Clarke MF: The biology of cancer stem cells. Annu Rev Cell Dev Biol 23: 675-699, 2007.

4 Geißler C, Hambek M, Leinung M, Diensthuber M, Gassner D, Stöver $\mathrm{T}$ and Wagenblast $\mathrm{J}$ : The challenge of tumor heterogeneity - different phenotypes of cancer stem cells in a head and neck squamous cell carcinoma xenograft mouse model. In Vivo 26: 593-598, 2012.

$5 \mathrm{Yu}$ Y, Ramena G and Elble RC: The role of cancer stem cells in relapse of solid tumors. Front Biosci (Elite Ed) 4: 1528-1541, 2012.

6 Malik B and Nie D: Cancer stem cells and resistance to chemo and radio therapy. Front Biosci (Elite Ed) 4: 2142-2149, 2012.

7 Abdullah LN and Chow EK: Mechanisms of chemoresistance in cancer stem cells. Clin Transl Med 2: 3, 2013.
8 Singh SK, Clarke ID, Terasaki M, Bonn VE, Hawkins C, Squire $\mathrm{J}$ and Dirks PB: Identification of a cancer stem cell in human brain tumors. Cancer Res 63: 5821-5828, 2003.

9 Shakhova O and Sommer L: Testing the cancer stem cell hypothesis in melanoma: the clinics will tell. Cancer Lett 338 : 74-81, 2013.

10 Ma L, Lai D, Liu T, Cheng W and Guo L: Cancer stem-like cells can be isolated with drug selection in human ovarian cancer cell line SKOV3. Acta Biochim Biophys Sin (Shanghai) 42: 593-602, 2010.

11 Al-Hajj M, Wicha MS, Benito-Hernandez A, Morrison SJ and Clarke MF: Prospective identification of tumorigenic breast cancer cells. Proc Natl Acad Sci USA 100: 3983-3988, 2003.

12 Ricci-Vitiani L, Lombardi DG, Pilozzi E, Biffoni M, Todaro M, Peschle $\mathrm{C}$ and De Maria R: Identification and expansion of human colon-cancer-initiating cells. Nature 445: 111-115, 2007.

13 Ma S, Chan KW, Hu L, Lee TK, Wo JY, Ng IO, Zheng BJ and Guan XY: Identification and characterization of tumorigenic liver cancer stem/progenitor cells. Gastroenterology 132: 25422556, 2007.

14 Passegué E, Jamieson CH, Ailles LE and Weissman IL: Normal and leukemic hematopoiesis: are leukemias a stem cell disorder or a reacquisition of stem cell characteristics? Proc Natl Acad Sci USA 100(Suppl 1): 11842-11849, 2003.

15 Lee J, Kotliarova S, Kotliarov Y, Li A, Su Q, Donin NM, Pastorino S, Purow BW, Christopher N, Zhang W, Park JK and Fine HA: Tumor stem cells derived from glioblastomas cultured in bFGF and EGF more closely mirror the phenotype and genotype of primary tumors than do serum-cultured cell lines. Cancer Cell 9: 391-403, 2006.

16 Lee $\mathrm{CH}$, Yu CC, Wang BY and Chang WW: Tumorsphere as an effective in vitro platform for screening anti-cancer stem cell drugs. Oncotarget 7: 1215-1226, 2016.

17 Avital I, Stojadinovic A, Wang H, Mannion C, Cho WC, Wang $\mathrm{J}$ and Man YG: Isolation of stem cells using spheroids from fresh surgical specimen: an analytic mini-review. Cancer Genomics Proteomics 11: 57-65, 2014.

18 Brescia P, Ortensi B, Fornasari L, Levi D, Broggi G, Pelicci G. Brescia P, Ortensi B, Fornasari L, Levi D, Broggi G and Pelicci G: CD133 is essential for glioblastoma stem cell maintenance. Stem Cells 31: 857-869, 2013.

19 Marhaba R, Klingbeil P, Nuebel T, Nazarenko I, Buechler MW and Zoeller M: CD44 and EpCAM: cancer-initiating cell markers. Curr Mol Med 8: 784-804, 2008.

20 Moore S, McDiarmid LA and Hughes TP: Stem cell factor and chronic myeloid leukemia CD34+ cells. Leuk Lymphoma 38: 211-220, 2000.

21 Sahlberg SH, Spiegelberg D, Glimelius B, Stenerlöw B and Nestor M: Evaluation of cancer stem cell markers CD133, CD44, CD24: association with AKT isoforms and radiation resistance in colon cancer cells. PLoS One 9: e94621, 2014.

22 Wilson BJ, Saab KR, Ma J, Schatton T, Pütz P, Zhan Q, Murphy GF, Gasser M, Waaga-Gasser AM, Frank NY and Frank MH: ABCB5 maintains melanoma-initiating cells through a proinflammatory cytokine signaling circuit. Cancer Res 74: 4196-4207, 2014.

23 Miyata $T$, Oyama $T$, Yoshimatsu $T$, Higa H, Kawano D, Sekimura A, Yamashita N, So T and Gotoh A: The clinical significance of cancer stem cell markers ALDH1A1 and CD133 in lung adenocarcinoma. Anticancer Res 37: 2541-2547, 2017. 
$24 \mathrm{Lv}$ J and Shim JS: Existing drugs and their application in drug discovery targeting cancer stem cells. Arch Pharm Res 38: 1617-1626, 2015.

25 Abubaker K, Luwor RB, Zhu H, McNally O, Quinn MA, Burns CJ, Thompson EW, Findlay JK and Ahmed N: Inhibition of the JAK2/STAT3 pathway in ovarian cancer results in the loss of cancer stem cell-like characteristics and a reduced tumor burden. BMC Cancer 14: 317, 2014.

26 Curtin JC and Lorenzi MV: Drug discovery approaches to target Wnt signaling in cancer stem cells. Oncotarget 1: 552$566,2010$.

27 Takebe N, Miele L, Harris PJ, Jeong W, Bando H, Kahn M, Yang SX and Ivy SP: Targeting Notch, Hedgehog, and Wnt pathways in cancer stem cells: clinical update. Nat Rev Clin Oncol 12: 445-464, 2015.

28 Seto K, Sakabe T, Itaba N, Azumi J, Oka H, Morimoto M, Umekita Y and Shiota G: A novel small-molecule WNT inhibitor, IC-2, has the potential to suppress liver cancer stem cells. Anticancer Res 37: 3569-3579, 2017.

29 Oktem G, Sercan O, Guven U, Uslu R, Uysal A, Goksel G, Ayla $S$ and Bilir A: Cancer stem cell differentiation: TGF $\beta 1$ and versican may trigger molecules for the organization of tumor spheroids. Oncol Rep 32: 641-649, 2014.

30 Scatena R, Bottoni P, Pontoglio A and Giardina B: The proteomics of cancer stem cells: potential clinical applications for innovative research in oncology. Proteomics Clin Appl 5: 590-602, 2011.

31 Kranenburg O, Emmink BL, Knol J, van Houdt WJ, Rinkes IH and Jimenez CR: Proteomics in studying cancer stem cell biology. Expert Rev Proteomics 9: 325-336, 2012.

32 Wang J, Trowbridge JJ, Rao S and Orkin SH: Proteomic studies of stem cells. StemBook [Internet] Cambridge (MA) Harvard Stem Cell Institute, 2008.

33 Bantscheff M, Scholten A and Heck AJ: Revealing promiscuous drug-target interactions by chemical proteomics. Drug Discov Today 14: 1021-1029, 2009.

34 Liu Y and Guo M: Chemical proteomic strategies for the discovery and development of anticancer drugs. Proteomics 14: 399-411, 2014

35 Getie-Kebtie M, Lazarev A, Eichelberger M and Alterman M: Label-free mass spectrometry-based relative quantification of proteins separated by one-dimensional gel electrophoresis. Anal Biochem 409: 202-212, 2011.

36 Görg A, Weiss W and Dunn MJ: Current two-dimensional electrophoresis technology for proteomics. Proteomics 4: 36653685, 2004.

37 Cho YT, Su H, Wu WJ, Wu DC, Hou MF, Kuo CH and Shiea $\mathrm{J}$ : Biomarker Characterization by MALDI-TOF/MS. Adv Clin Chem 69: 209-254, 2015.

38 Wilm M, Shevchenko A, Houthaeve T, Breit S, Schweigerer L, Fotsis T and Mann M: Femtomole sequencing of proteins from polyacrylamide gels by nano-electrospray mass spectrometry. Nature 379: 466-469, 1996.

39 Viswanathan S, Unlü M and Minden JS: Two-dimensional difference gel electrophoresis. Nat Protoc 1: 1351-1358, 2006.

40 Wasinger VC, Zeng M and Yau Y: Current status and advances in quantitative proteomic mass spectrometry. Int J Proteomics 2013: 180605, 2013

41 Wu WW, Wang G, Baek SJ and Shen RF: Comparative study of three proteomic quantitative methods, DIGE, cICAT, and
iTRAQ, using 2D gel- or LC-MALDI TOF/TOF. J Proteome Res 5: 651-658, 2006.

42 Ong SE, Blagoev B, Kratchmarova I, Kristensen DB, Steen H, Pandey A and Mann M: Stable isotope labeling by amino acids in cell culture, SILAC, as a simple and accurate approach to expression proteomics. Mol Cell Proteomics 1: 376-386, 2002.

43 Shiio Y and Aebersold R: Quantitative proteome analysis using isotope-coded affinity tags and mass spectrometry. Nat Protoc 1: 139-145, 2006.

44 Rauniyar N and Yates JR 3rd: Isobaric labeling-based relative quantification in shotgun proteomics. J Proteome Res 13: 52935309, 2014.

45 Boellner S and Becker KF: Reverse phase protein arraysquantitative assessment of multiple biomarkers in biopsies for clinical use. Microarrays (Basel) 4: 98-114, 2015.

46 Pierobon M, Wulfkuhle J, Liotta L and Petricoin E: Application of molecular technologies for phosphoproteomic analysis of clinical samples. Oncogene 34: 805-814, 2015.

47 Sutton CW: The role of targeted chemical proteomics in pharmacology. Br J Pharmacol 166: 457-475, 2012.

48 Jung HJ and Kwon HJ: Target deconvolution of bioactive small molecules: the heart of chemical biology and drug discovery. Arch Pharm Res 38: 1627-1641, 2015.

49 Rix U, Hantschel O, Dürnberger G, Remsing Rix LL, Planyavsky M, Fernbach NV, Kaupe I, Bennett KL, Valent P, Colinge J, Köcher T and Superti-Furga G: Chemical proteomic profiles of the BCR-ABL inhibitors imatinib, nilotinib, and dasatinib reveal novel kinase and nonkinase targets. Blood 110: 4055-4063, 2007.

50 Lomenick B, Hao R, Jonai N, Chin RM, Aghajan M, Warburton S, Wang J, Wu RP, Gomez F, Loo JA, Wohlschlegel JA, Vondriska TM, Pelletier J, Herschman HR, Clardy J, Clarke CF and Huang J: Target identification using drug affinity responsive target stability (DARTS). Proc Natl Acad Sci USA 106: 21984-21989, 2009

51 Chang J, Kim Y and Kwon HJ: Advances in identification and validation of protein targets of natural products without chemical modification. Nat Prod Rep 33: 719-730, 2016.

52 Wang N, Wang Z, Peng C, You J, Shen J, Han S and Chen J: Dietary compound isoliquiritigenin targets GRP78 to chemosensitize breast cancer stem cells via $\beta$-catenin/ABCG2 signaling. Carcinogenesis 35: 2544-2554, 2014.

53 Macias AT, Williamson DS, Allen N, Borgognoni J, Clay A, Daniels Z, Dokurno P, Drysdale MJ, Francis GL, Graham CJ, Howes R, Matassova N, Murray JB, Parsons R, Shaw T, Surgenor AE, Terry L, Wang Y, Wood M and Massey AJ: Adenosine-derived inhibitors of $78 \mathrm{kDa}$ glucose regulated protein (Grp78) ATPase: insights into isoform selectivity. J Med Chem 54: 4034-4041, 2011.

54 Dong D, Ni M, Li J, Xiong S, Ye W, Virrey JJ, Mao C, Ye R, Wang M, Pen L, Dubeau L, Groshen S, Hofman FM and Lee AS: Critical role of the stress chaperone GRP78/BiP in tumor proliferation, survival, and tumor angiogenesis in transgeneinduced mammary tumor development. Cancer Res 68: 498$505,2008$.

55 Ohtsubo K and Marth JD: Glycosylation in cellular mechanisms of health and disease. Cell 126: 855-867, 2006.

56 Woods RJ, Edge CJ and Dwek RA: Protein surface oligosaccharides and protein function. Nat Struct Biol 1: 499501,1994 
57 Rudd PM, Elliott T, Cresswell P, Wilson IA and Dwek RA: Glycosylation and the immune system. Science 291: 23702376, 2001.

58 Hakomori S: Aberrant glycosylation in tumors and tumorassociated carbohydrate antigens. Adv Cancer Res 52: 257-331, 1989.

59 Reis CA, Osorio H, Silva L, Gomes C and David L: Alterations in glycosylation as biomarkers for cancer detection. J Clin Pathol 63: 322-329, 2010.

60 Yanagisawa $M$ and Yu RK: The expression and functions of glycoconjugates in neural stem cells. Glycobiology 17: 57R74R, 2007.

61 He J, Liu Y, Xie X, Zhu T, Soules M, DiMeco F, Vescovi AL, Fan $X$ and Lubman DM: Identification of cell surface glycoprotein markers for glioblastoma-derived stem-like cells using a lectin microarray and LC-MS/MS approach. J Proteome Res 9: 2565-2572, 2010.

$62 \mathrm{Zhu} \mathrm{J}, \mathrm{He} \mathrm{J}$, Liu Y, Simeone DM and Lubman DM: Identification of glycoprotein markers for pancreatic cancer CD24 ${ }^{+} \mathrm{CD} 44+$ stem-like cells using nano-LC-MS/MS and tissue microarray. J Proteome Res 11: 2272-2281, 2012.

63 Wang Y, Wu SL and Hancock WS: Approaches to the study of $\mathrm{N}$-linked glycoproteins in human plasma using lectin affinity chromatography and nano-HPLC coupled to electrospray linear ion trap--Fourier transform mass spectrometry. Glycobiology 16: 514-523, 2006.

64 Qiu R and Regnier FE: Use of multidimensional lectin affinity chromatography in differential glycoproteomics. Anal Chem 77: 2802-2809, 2005.

65 Kaji H, Saito H, Yamauchi Y, Shinkawa T, Taoka M, Hirabayashi J, Kasai K, Takahashi $\mathrm{N}$ and Isobe T: Lectin affinity capture, isotope-coded tagging and mass spectrometry to identify $\mathrm{N}$ linked glycoproteins. Nat Biotechnol 21: 667-672, 2003.

66 Dai L, Liu Y, He J, Flack CG, Talsma CE, Crowley JG, Muraszko KM, Fan X and Lubman DM: Differential profiling studies of $\mathrm{N}$-linked glycoproteins in glioblastoma cancer stem cells upon treatment with $\gamma$-secretase inhibitor. Proteomics 11: 4021-4028, 2011.

67 Fan X, Khaki L, Zhu TS, Soules ME, Talsma CE, Gul N, Koh C, Zhang J, Li YM, Maciaczyk J, Nikkhah G, Dimeco F, Piccirillo S, Vescovi AL and Eberhart CG: NOTCH pathway blockade depletes CD133-positive glioblastoma cells and inhibits growth of tumor neurospheres and xenografts. Stem Cells 28: 5-16, 2010.

68 Yogeeswaran G and Salk PL: Metastatic potential is positively correlated with cell surface sialylation of cultured murine tumor cell lines. Science 212: 1514-1516, 1981.

69 Moriwaki K, Okudo K, Haraguchi N, Takeishi S, Sawaki H, Narimatsu H, Tanemura M, Ishii H, Mori M and Miyoshi E: Combination use of anti-CD133 antibody and SSA lectin can effectively enrich cells with high tumorigenicity. Cancer Sci 102: 1164-1170, 2011.

70 Hermann PC, Huber SL, Herrler T, Aicher A, Ellwart JW, Guba M, Bruns CJ and Heeschen C: Distinct populations of cancer stem cells determine tumor growth and metastatic activity in human pancreatic cancer. Cell Stem Cell 1: 313-323, 2007.

71 Azuma K, Serada S, Takamatsu S, Terao N, Takeishi S, Kamada Y, Naka T and Miyoshi E: Identification of sialylated glycoproteins in Doxorubicin-treated hepatoma cells with glycoproteomic analyses. J Proteome Res 13: 4869-4877, 2014.
72 Cohen P: The regulation of protein function by multisite phosphorylation - a 25 year update. Trends Biochem Sci 25: 596-601, 2000.

73 Cohen P: The origins of protein phosphorylation. Nat Cell Biol 4: E127-130, 2002.

74 Hunter T: Signaling--2000 and beyond. Cell 100: 113-127, 2000.

75 Easty D, Gallagher W and Bennett DC: Protein tyrosine phosphatases, new targets for cancer therapy. Curr Cancer Drug Targets 6: 519-532, 2006.

76 Harsha HC and Pandey A: Phosphoproteomics in cancer. Mol Oncol 4: 482-495, 2010.

77 Morris MK, Chi A, Melas IN and Alexopoulos LG: Phosphoproteomics in drug discovery. Drug Discov Today 19: 425-432, 2014.

78 Pierobon M, Wulfkuhle J, Liotta L and Petricoin E: Application of molecular technologies for phosphoproteomic analysis of clinical samples. Oncogene 34: 805-814, 2015.

79 Williamson AJ, Pierce A, Jaworska E, Zhou C, Aspinall-O'Dea M, Lancashire L, Unwin RD, Abraham SA, Walker MJ, Cadecco S, Spooncer E, Holyoake TL and Whetton AD: A specific PTPRC/CD45 phosphorylation event governed by stem cell chemokine CXCL12 regulates primitive hematopoietic cell motility. Mol Cell Proteomics 12: 33193329, 2013.

80 Signore M, Pelacchi F, di Martino S, Runci D, Biffoni M, Giannetti S, Morgante L, De Majo M, Petricoin EF, Stancato L, Larocca LM, De Maria R, Pallini R and Ricci-Vitiani L: Combined PDK1 and CHK1 inhibition is required to kill glioblastoma stem-like cells in vitro and in vivo. Cell Death Dis 5: e1223, 2014

81 Lamb R, Harrison H, Hulit J, Smith DL, Lisanti MP and Sotgia F: Mitochondria as new therapeutic targets for eradicating cancer stem cells: Quantitative proteomics and functional validation via MCT1/2 inhibition. Oncotarget 5: 11029-11037, 2014.

82 Ahler E, Sullivan WJ, Cass A, Braas D, York AG, Bensinger SJ, Graeber TG and Christofk HR: Doxycycline alters metabolism and proliferation of human cell lines. PLoS One 8: e64561, 2013.

83 Zhang L, Ging NC, Komoda T, Hanada T, Suzuki T and Watanabe $\mathrm{K}$ : Antibiotic susceptibility of mammalian mitochondrial translation. FEBS Lett 579: 6423-6427, 2005.

84 Lamb R, Ozsvari B, Lisanti CL, Tanowitz HB, Howell A, Martinez-Outschoorn UE, Sotgia F and Lisanti MP: Antibiotics that target mitochondria effectively eradicate cancer stem cells, across multiple tumor types: treating cancer like an infectious disease. Oncotarget 6: 4569-4584, 2015.

85 Lamb R, Fiorillo M, Chadwick A, Ozsvari B, Reeves KJ, Smith DL, Clarke RB, Howell SJ, Cappello AR, Martinez-Outschoorn UE, Peiris-Pagès M, Sotgia F and Lisanti MP: Doxycycline down-regulates DNA-PK and radiosensitizes tumor initiating cells: Implications for more effective radiation therapy. Oncotarget 6: 14005-14025, 2015.

86 Davis AJ, Lee KJ and Chen DJ: The N-terminal region of the DNA-dependent protein kinase catalytic subunit is required for its DNA double-stranded break-mediated activation. J Biol Chem 288: 7037-7046, 2013.

87 Davis AJ, Chen BP and Chen DJ: DNA-PK: a dynamic enzyme in a versatile DSB repair pathway. DNA Repair (Amst) 17: 21$29,2014$. 
88 Papeta N, Zheng Z, Schon EA, Brosel S, Altintas MM, Nasr SH, Reiser J, D'Agati VD and Gharavi AG: Prkdc participates in mitochondrial genome maintenance and prevents Adriamycin-induced nephropathy in mice. J Clin Invest 120 : 4055-4064, 2010.

89 Ciszewski WM, Tavecchio M, Dastych J and Curtin NJ: DNAPK inhibition by NU7441 sensitizes breast cancer cells to ionizing radiation and doxorubicin. Breast Cancer Res Treat 143: 47-55, 2014.

90 Wente SR and Rout MP: The nuclear pore complex and nuclear transport. Cold Spring Harb Perspect Biol 2: a000562, 2010.

91 Raices $M$ and D'Angelo MA: Nuclear pore complexes and regulation of gene expression. Curr Opin Cell Biol 46: 26-32, 2017.

$92 \mathrm{Xu} \mathrm{S}$ and Powers MA: Nuclear pore proteins and cancer. Semin Cell Dev Biol 20: 620-630, 2009.

93 Liu HL, Chen Y, Cui GH, Wu QL, He J, Chen WH and Zhou JF: Deguelin regulates nuclear pore complex proteins Nup98 and Nup88 in U937 cells in vitro. Acta Pharmacol Sin 26: 1265-1273, 2005.

94 Copland M, Pellicano F, Richmond L, Allan EK, Hamilton A, Lee FY, Weinmann R and Holyoake TL: BMS-214662 potently induces apoptosis of chronic myeloid leukemia stem and progenitor cells and synergizes with tyrosine kinase inhibitors. Blood 111: 2843-2853, 2008.

95 Balabanov S, Evans CA, Abraham SA, Pellicano F, Copland M, Walker MJ, Whetton AD and Holyoake TL: Quantitative proteomics analysis of BMS-214662 effects on CD34 positive cells from chronic myeloid leukaemia patients. Proteomics 13: 153-168, 2013.

96 Thiery JP, Acloque H, Huang RY and Nieto MA: Epithelialmesenchymal transitions in development and disease. Cell 139: 871-890, 2009.

97 Singh A and Settleman J: EMT, cancer stem cells and drug resistance: an emerging axis of evil in the war on cancer. Oncogene 29: 4741-4751, 2010.

98 Donnenberg VS and Donnenberg AD: Stem cell state and the epithelial-to-mesenchymal transition: Implications for cancer therapy. J Clin Pharmacol 55: 603-619, 2015.

99 Liu F, Kong X, Lv L and Gao J: TGF- $\beta 1$ acts through miR-155 to down-regulate TP53INP1 in promoting epithelialmesenchymal transition and cancer stem cell phenotypes. Cancer Lett 359: 288-298, 2015.
100 Paz-Ares L, Soulières D, Melezínek I, Moecks J, Keil L, Mok $\mathrm{T}$, Rosell $\mathrm{R}$ and Klughammer B: Clinical outcomes in nonsmall-cell lung cancer patients with EGFR mutations: pooled analysis. J Cell Mol Med 14: 51-69, 2010.

101 Augustin A, Lamerz J, Meistermann H, Golling S, Scheiblich S, Hermann JC, Duchateau-Nguyen G, Tzouros M, Avila DW, Langen $\mathrm{H}$, Essioux $\mathrm{L}$ and Klughammer B: Quantitative chemical proteomics profiling differentiates erlotinib from gefitinib in EGFR wild-type non-small cell lung carcinoma cell lines. Mol Cancer Ther 12: 520-529, 2013.

102 Padhye S, Dandawate P, Yusufi M, Ahmad A and Sarkar FH: Perspectives on medicinal properties of plumbagin and its analogs. Med Res Rev 32: 1131-1158, 2012.

103 Pan ST, Qin Y, Zhou ZW, He ZX, Zhang X, Yang T, Yang YX, Wang D, Zhou SF and Qiu JX: Plumbagin suppresses epithelial to mesenchymal transition and stemness via inhibiting Nrf2mediated signaling pathway in human tongue squamous cell carcinoma cells. Drug Des Devel Ther 9: 5511-5551, 2015.

104 Mills GB and Moolenaar WH: The emerging role of lysophosphatidic acid in cancer. Nat Rev Cancer 3: 582-591, 2003.

105 Jeon ES, Moon HJ, Lee MJ, Song HY, Kim YM, Cho M, Suh DS, Yoon MS, Chang CL, Jung JS and Kim JH: Cancer-derived lysophosphatidic acid stimulates differentiation of human mesenchymal stem cells to myofibroblast-like cells. Stem Cells 26: 789-797, 2008.

106 Shin SH, Kim J, Heo SC, Kwon YW, Kim YM, Kim IS, Lee TG and Kim JH: Proteomic identification of betaig-h3 as a lysophosphatidic acid-induced secreted protein of human mesenchymal stem cells: paracrine activation of A549 lung adenocarcinoma cells by betaig-h3. Mol Cell Proteomics 11: M111.012385, 2012.

107 Anderson L and Seilhamer J: A comparison of selected mRNA and protein abundances in human liver. Electrophoresis 18 : 533-537, 1997.

108 Tyers M and Mann M: From genomics to proteomics. Nature 422: 193-197, 2003.

Received June 30, 2017

Revised July 18, 2017

Accepted July 20, 2017 